\title{
Studi Peningkatan Kemampuan Galangan Kapal di Jawa Timur untuk Mendukung Program Pengadaan Kapal Penangkap Ikan Nasional oleh Kementerian Kelautan dan Perikanan
}

\author{
Maynar Muhammad Alfath, Sri Rejeki Wahyu Pribadi, dan Soejitno \\ Jurusan Teknik Perkapalan, Fakultas Teknologi Kelautan, ITS, Institut Teknologi Sepuluh Nopember (ITS) \\ Jl. Arief Rahman Hakim, Surabaya 60111 Indonesia \\ e-mail : sri-rejeki@na.its.ac.id
}

\begin{abstract}
Abstrak-Kementerian Kelautan dan Perikanan mencanangkan program pengadaan 3280 kapal penangkap ikan dengan bahan dasar fiberglass di tahun 2016. Keseluruhan kapal akan dibangun menggunakan material fiberglass. Hal ini tidak sebanding dengan jumlah galangan kapal fiber di Indonesia yang lebih didominasi oleh galangan kapal kayu, terlebih Jawa Timur. Tujuan Tugas Akhir ini adalah untuk mengevaluasi kondisi eksisting galangan kapal kayu di Jawa Timur, serta melakukan analisis teknis dan ekonomis kebutuhan pengembangan galangan kapal kayu agar mampu berperan dalam pembangunan kapal penangkap ikan oleh Kementerian Kelautan dan Perikanan. Didalam pengerjaan Tugas Akhir ini, dilakukan survey ke galangan kapal kayu dan fiber di Jawa Timur. Studi literatur dilakukan mengenai kapal penangkap ikan, proses pembangunan kapal fiber, dan analisis kelayakan investasi. Dari kriteria peserta lelang pengadaan kapal penangkap ikan, dibuat strategi pengembangan berupa persiapan sumberdaya manusia galangan, peralatan galangan, serta komposisi workshop galangan. Dilakukan juga perhitungan ekonomis mengenai analisis kelayakan investasi pengembangan galangan. Hasil yang didapatkan adalah galangan kapal kayu belum memiliki SDM minimal lulusan D3 Teknik Perkapalan sebagai syarat kelayakan galangan mengikuti lelang pembangunan kapal. Komposisi manajemen galangan berupa direktur utama (owner), kepala produksi (minimal D3 Teknik Perkapalan), tenaga produksi, tenaga kelistrikan (minimal SMK Listrik), administrasi dan keuangan, serta bagian pemasaran. Pengembangan kompetensi tenaga produksi membutuhkan 35 materi pelatihan pembangunan kapal fiber selama 160 jam. Peralatan produksi kapal fiber yang dibutuhkan adalah kebutuhan peralatan dari metode produksi hand lay-up. Luas workshop kapal fiber yang dibutuhkan adalah $1350 \mathrm{~m}^{2}$. Pengembangan galangan kapal kayu membutuhkan investasi sebesar Rp. 1.131.213.000,-. Perhitungan kelayakan investasi metode NPV dengan suku bunga 13,39\% menghasilkan pengembalian investasi di tahun ke 6 setelah pengembangan galangan dilakukan. Dan hasil perhitungan dari IRR menunjukkan besaran bunga yang masih layak untuk dilakukan investasi mencapai $18,08 \%$, lebih besar dari suku bunga.
\end{abstract}

Kata Kunci-Galangan Kapal Kayu , Kapal Fiber, Kapal Penangkap Ikan, Kementerian Kelautan dan Perikanan, Peningkatan Kemampuan Galangan.

\section{PENDAHULUAN}

$\mathrm{P}$ EMBANGUNAN kapal Inka Mina di tahun 2010 hingga 2014 hanya mampu membangun kapal sejumlah 878 unit dari target total 1046 unit [1]. Keterlambatan ini tentu memerlukan beberapa evaluasi, dan salah satu yang diperlukan adalah evaluasi kemampuan pembangunan kapal dari galangan kapal di Indonesia. Dibawah kepemimpinan Menteri Susi Pudjiastuti, Kementerian Kelautan dan Perikanan mencanangkan program pengadaan kapal penangkap ikan sebanyak 3280 kapal. Ukuran-ukuran kapal yang hendak dibangun diantaranya $<5$ GT, 5 GT, 10 GT, 20 GT dan 30 GT [2].

Badan Koordinasi Penanaman Modal (BKPM) memiliki data 12 wilayah yang potensial untuk pengembangan industri galangan kapal. Kedua belas wilayah tersebut adalah Riau, Kepulauan Riau, Sumatera Selatan, Lampung, Kalimantan Barat, Jawa Tengah, Jawa Timur, Sulawesi Utara, Papua, Kawasan Perdagangan Bebas Batam, Wongsorejo Industrial Estate Banyuwangi serta Kawasan Industri Java Integrated Industrial Port Estate (JIIPE) di Jawa Timur. Dari kedua belas wilayah tersebut, Jawa Timur termasuk daerah yang berpotensi baik untuk industri reparasi maupun bangunan baru [3]. Dengan adanya potensi pengembangan galangan kapal di wilayah Jawa Timur, penulis hendak melakukan studi terhadap galangan kapal di Jawa Timur, agar dapat mendukung program pengadaan kapal penangkap ikan oleh Kementerian Kelautan dan Perikanan.

Berbeda dengan program pengadaan kapal Inka Mina yang dibangun menggunakan bahan dasar kayu dan fiber, program pengadaan 3280 kapal ikan tahun 2016 akan dibangun seluruhnya menggunakan bahan dasar fiberglass. Di Jawa Timur, terdapat total 151 unit usaha galangan kapal rakyat. Yaitu 143 unit usaha berupa galangan kapal kayu, dan 8 lainnya berupa galangan kapal fiber [4]. Dengan adanya ketimpangan jumlah galangan kapal fiber dibandingkan galangan kapal kayu, peneliti hendak mengadakan penelitian dengan judul "Studi Peningkatan Kemampuan Galangan Kapal di Jawa Timur untuk Mendukung Program Pengadaan Kapal Penangkap Ikan Nasional oleh Kementerian Kelautan dan Perikanan” dengan memfokuskan pada pengembangan galangan kapal kayu agar mampu membangun kapal fiber.

\section{II.LANDASAN TEORI}

\section{A. Kapal Penangkap Ikan}

Kapal perikanan adalah kapal, perahu, atau alat apung lain yang digunakan untuk melakukan penangkapan ikan, mendukung operasi penangkapan ikan, pembudidayaan ikan, pengangkutan ikan, pengolahan ikan, pelatihan perikanan, dan penelitian atau eksplorasi perikanan. Sedangkan kapal penangkap ikan, adalah kapal yang secara khusus dipergunakan untuk menangkap ikan termasuk 
menampung, menyimpan, dan mendinginkan atau mengawetkan [5].

\section{B. Pembangunan Kapal Fiber}

Secara garis besar, proses pembangunan kapal fiber terdiri dari tiga bagian, yaitu pembuatan cetakan kapal, proses laminasi pembentukan bagian kapal, dan assembly berupa penyatuan badan kapal [6]. Cetakan kapal yang dibuat terdiri dari rangka cetakan atau plug, juga alas cetakan atau yang disebut mould.

Proses laminasi bagian kapal, terdiri dari laminasi bagian lambung, bangunan atas, serta gading-gading kapal. Terdapat tiga teknik laminasi kapal fiber, yaitu hand lay-up, chopper gun, serta vacuum infusion. Di Indonesia, yang paling banyak digunakan adalah metode hand lay-up. Selanjutnya, bagian lambung kapal dan bangunan atas yang sebelumnya dicetak di tempat yang berbeda, dilakukan penyatuan atau assembly.

\section{Strategi Pengembangan Galangan Kapal}

Strategi mengembangkan galangan kapal yang dilakukan, mengacu pada dasar pembuatan galangan kapal. Diantaranya adalah mengenai perencanaan tata letak workshop galangan kapal, dan menghitung kebutuhan peralatan produksi. Alur perencanaan tata letak galangan adalah membuat aliran material selama proses produksi dilakukan, membuat blok diagram perencanaan tata letak workshop, membuat detail diagram dengan terdapat perhitungan luasan masing-masing workshop, memasukkan diagram dengan perhitungan kedalam perencanaan tata letak galangan [7]. Prinsip dasar perencanaan fasilitas memperhatikan tolak ukur dari metode produksi, unjuk kerja / performance, utilization atau waktu kerja efektif alat [8].

\section{D.Analisis Kelayakan Investasi}

Analisis kelayakan finansial diperlukan untuk pengecekan seberapa layak usaha dijalankan. Beberapa metode untuk melakukan pengecekan diantaranya adalah metode net present value, dan internal rate of return [9].

\section{URAIAN PENELITIAN}

\section{A. Pendahuluan}

Pada penelitian ini, akan dilakukan mengenai studi peningkatan kemampuan galangan kapal kayu di Jawa Timur, agar mampu membangun kapal fiber sesuai dengan kebutuhan pembangunan kapal penangkap ikan oleh Kementerian Kelautan dan Perikanan (KKP). Studi pengembangan kemampuan galangan dilakukan dengan cara menjadikan syarat kelayakan peserta lelang pembangunan kapal penangkap ikan oleh KKP sebagai parameter pengembangan galangan. Untuk perhitungan teknis, dipilih galangan kapal berpotensi untuk dikembangkan, yaitu UD. Duta Merpati di Lamongan sebagai studi kasus perhitungan pemngembangan galangan kapal kayu.

\section{B. Identifikasi KondisiEksisting Pembangunan Kapal}

Identifikasi dilakukan dengan mengumpulkan data baik data primer maupun data sekunder. Data primer yang dibutuhkan didapat dari Kementerian Kelautan dan Perikanan tentang kebijakan pengadaan kapal penangkap ikan, serta kepada galangan-galangan kapal yang ada di Jawa Timur yang berpotensi melakukan pembangunan kapal penangkap ikan hasil kebijakan Kementerian Kelautan dan
Perikanan mengenai kondisi pembangunan kapal kayu dan kondisi pembangunan kapal fiber di Jawa Timur.

Data sekunder yang dibutuhkan berupa data dari Dinas Perindustrian dan Perdagangan Provinsi Jawa Timur untuk memperoleh data galangan kapal kayu dan fiber yang ada dan terdaftar di Jawa Timur

Data primer yang didapatkan dari KKP tentang jumlah kapal dan anggaran biaya pembangunan masing-masing kapal penangkap ikan ditunjukkan pada Tabel 1berikut ini.

\begin{tabular}{cccc}
\multicolumn{4}{c}{ Tabel 1. Data Program Pengadaan Kapal } \\
\hline \hline Ukuran Kapal & Jumlah & Harga Satuan & Total Biaya \\
\hline Ukuran < 5 GT & 1,000 & $300,000,000$ & $300,000,000,000$ \\
Ukuran 5 GT & 1,000 & $450,000,000$ & $450,000,000,000$ \\
Ukuran 10 GT & 1,000 & $900,000,000$ & $900,000,000,000$ \\
Ukuran 20 GT & 250 & $1,450,000,000$ & $362,500,000,000$ \\
Ukuran 30 GT & 30 & $1,850,000,000$ & $55,500,000,000$ \\
\hline \hline
\end{tabular}

(Sumber Kementerian Kelautan dan Perikanan, 2015)

Kondisi pembangunan kapal kayu saat ini, kapal dibangun dengan tanpa menggunakan desain awal kapal. Akan tetapi, pembangunan kapal mengandalkan intuisi dari tenaga produksi galangan kapal kayu. Lokasi pembangunan kapal kayu hampir semua menggunakan lahan pesisir pantai atau tanah milik desa. Hanya sebagian kecil yang memiliki lahan sendiri.

Mengenai kondisi pembangunan kapal fiber, dalam keseluruhan proses pembangunannya dari awal pembangunan hingga selesai, kapal tidak mengalami pemindahan lokasi. Akan tetapi, material dan peralatan produksi yang dipindahkan mendekati kapal. Tidak ada pembagian area kerja atau workshop, sehingga tidak cocok untuk produksi kapal dengan tipe mass product.

Data-data galangan kapal kayu dan fiber di Jawa Timur yang didapatkan dari Dinas Perindustrian dan Perdagangan adalah sebagai berikut ini.

\begin{tabular}{|c|c|c|}
\hline 1. Banyuwangi & : 41 Gal. Kapal Kayu & : 1 Gal. Kapal Fiber \\
\hline 2. Surabaya & : 1 Gal. Kapal Kayu & : 1 Gal. Kapal Fiber \\
\hline 3. Lamongan & : 9 Gal. Kapal Kayu & : 0 Gal. Kapal Fiber \\
\hline 4. Pamekasan & : 7 Gal. Kapal Kayu & : 0 Gal. Kapal Fiber \\
\hline 5. Probolinggo & : 2 Gal. Kapal Kayu & : 2 Gal. Kapal Fiber \\
\hline 6. Pacitan & : 0 Gal. Kapal Kayu & : 2 Gal. Kapal Fiber \\
\hline 7. Sidoarjo & : 0 Gal. Kapal Kayu & : 1 Gal. Kapal Fiber \\
\hline 8. Pasuruan & : 30 Gal. Kapal Kayu & : 1 Gal. Kapal Fiber \\
\hline 9. Bangkalan & : 10 Gal. Kapal Kayu & : 0 Gal. Kapal Fiber \\
\hline 10. Sampang & : 2 Gal. Kapal Kayu & : 0 Gal. Kapal Fiber \\
\hline 11. Sumenep & : 10 Gal. Kapal Kayu & : 0 Gal. Kapal Fiber \\
\hline 12. Tulungagung & : 3 Gal. Kapal Kayu & : 0 Gal. Kapal Fiber \\
\hline 13. Tuban & : 23 Gal. Kapal Kayu & : 0 Gal. Kapal Fiber \\
\hline 14. Gresik & : 4 Gal. Kapal Kayu & : 0 Gal. Kapal Fiber \\
\hline Jumlah & : 143 Gal. Kapal Kayu & : 8 Gal. Kapal Fiber \\
\hline
\end{tabular}

\section{C.Pengembangan SDM Galangan Kapal Kayu}

Analisis kebutuhan sumberdaya manusia dilakukan mengacu pada standar yang telah ditentukan dalam syarat peserta lelang pembangunan kapal oleh KKP. Sehingga didapatkan minimal galangan memiliki tenaga kerja seperti :

- Tenaga ahli lulusan minimal D3 Teknik Perkapalan

- Tenaga teknis perkapalan

- Tenaga teknis kelistrikan minimal SMK

- Tenaga pelapis laminasi fiber

oleh karena itu, perencanaan SDM galangan direncanakan memiliki susunan komposisi manajemen galangan berupa direktur utama (owner), kepala produksi (minimal D3 Teknik Perkapalan), tenaga produksi, tenaga kelistrikan (minimal SMK Listrik), administrasi dan keuangan, serta bagian pemasaran.

Untuk analisis pengembangan SDM berupa pengembangan keterampilan tenaga produksi galangan 
kapal kayu, agar mampu membangun kapl fiber, dilakukan perbandingan antara keterampilan pekerja dengan keterampilan yang dibutuhkan dalam membangun kapal fiber. Perbandingan dilakukan di tiap proses pembangunan kapal. Setelah dilakukan perbandingan, akan dapat diketahui kebutuhan keterampilan yang harus dimiliki oleh tenaga kerja galangan kapal kayu agar mampu membangun kapal fiber.

Persiapan pengembangan galangan kapal kayu tradisional meliputi beberapa hal, seperti persiapan pengembangan sumber daya manusia, fasilitas produksi, serta biaya pengembangan yang dibutuhkan.

Dari perhitungan yang dilakukan, diketahui kebutuhan materi pelatihan sebanyak 35 materi yang terdiri dari teori dan praktek dengan total waktu sebanyak 160 Jam. Untuk merealisasikan pelatihan ketrampilan tenaga kerja produksi, Dinas Perindustrian dan Perdagangan Provinsi Jawa Timur memiliki patokan standart harga Rp. 2.500.000,- per 5 jam, sehingga biaya pelatihan yang dibutuhkan adalah sejumlah Rp. 80.000.000

\section{D.Pengembangan Fasilitas Galangan}

Pada dasarnya, peralatan yang dibutuhkan untuk melakukan pembangunan kapal fiber dapat dibedakan menjadi beberapa macam, yaitu Hand Tools (Peralatan Manual), Power Tools (Peralatan Listrik) serta Material Handling (Penanganan Material).

Telah dipilih galangan UD. Duta Merpati dengan kapasitas pembangunan kapal ukuran 30 GT di Lamongan. Data fasilitas peralatan galangan UD Duta merpati didapatkan pada saat survey. Dari kebutuhan peralatan produksi, dibandingkan dengan kepemilikan peralatan terkait, didapatkan kebutuhan investasi peralatan dipaparkan pada Tabel 2 berikut.

Tabel 2. Kebutuhan Peralatan Produksi Kapal Fiber 30 GT

\begin{tabular}{cc}
\hline \hline Jenis Peralatan & Kebutuhan Investasi \\
\hline Peralatan Hand Tools & 5.873 .000 \\
Peralatan Power Tools & 25.875 .000 \\
Peralatan Material Handling & 66.275 .000 \\
\hline Jumlah & $\mathbf{9 8 . 0 2 3 . 0 0 0}$ \\
\hline \hline
\end{tabular}

Dari pemaparan data diatas, dapat dilihat diperlukan setidaknya Rp. 98.023.000,- untuk melakukan investasi peralatan produksi kapal fiber ukuran 30 GT untuk galangan UD. Duta Merpati.

\section{E. Pengembangan Tata Letak Workshop Galangan}

Tata letak galangan kapal kayu untuk mampu membangun kapal fiber dianalisis dengan dasar area lahan yang dilakukan pengembangan adalah mili UD. Duta Merpati. Pengembangan tata letak workshop dibatasi untuk tidak melakukan penambahan lahan.

Kondisi pembangunan awal yang tidak adanya pembagian area kerja atau workshop, menyebabkan perlu dilakukan analisis mengenai kebutuhan workshop galangan kapal. Dengan berpatokan pada urutan proses produksi kapal fiber, didapatkan kebutuhan komposisi workshop galangan kapal diantaranya adalah kantor, bengkel kayu, workshop laminasi, bengkel assembly, bengkel pengecatan dan pendempulan, serta area peluncuran kapal.

Dilakukan perhitungan kebutuhan luasan masing-masing area workshop. Hasil yang didapatkan dari perhitungan luasan workshop dan bagian didalamnya dipaparkan sebagaimana berikut ini
a. Area Penyimpanan Papan Kayu
$(8 \times 2) \mathrm{m}^{2}$

b. Tempat Penyimpanan Peralatan Kayu (1x2) m²

c. Tempat Penyimpanan Peralatan Laminasi $(1 \mathrm{x} 2) \mathrm{m}^{2}$

d. Area Laminasi $(12 \times 21) \mathrm{m}^{2}$

e. Area Assembly $(12 \times 21) \mathrm{m}^{2}$

f. Area Pengecatan dan Pendempulan $(12 \times 21) \mathrm{m}^{2}$

g. Area Peluncuran $(21 \mathrm{x} 6) \mathrm{m}^{2}$

h. Tempat Penyimpanan Permesinan dan Kelistrikan (3x8) $\mathrm{m}^{2}$

i. Tempat Penyimpanan Perlengkapan Outfitting (3x8) $\mathrm{m}^{2}$

j. Area Penyimpanan Material Pengecatan dan Pendempulan (3x4) $\mathrm{m}^{2}$

k. Area Pembangunan Kapal Kayu (21x9) $\mathrm{m}^{2}$

l. Kantor $(6 \times 7) \mathrm{m}^{2}$

m. Mushola $(6 \times 5) \mathrm{m}^{2}$

n. Toilet $(6 \times 6) \mathrm{m}^{2}$

o. Tempat Penyimpanan Material Laminasi (3x8) $\mathrm{m}^{2}$

Setelah dibandingkan dengan tata letak workshop awal galangan kapal kayu UD. Duta Merpati, didapatkan tata letak workshop baru untuk UD. Duta merpati adalah sebagai berikut.

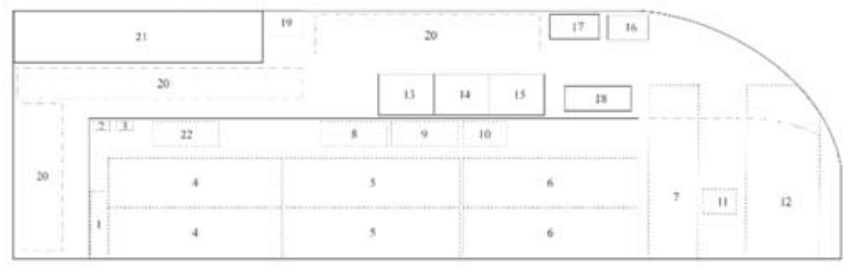

Gambar 1. Tata Letak Workshop Galangan UD. Duta Merpati Setelah Ditambahkan Workshop untuk Pembangunan Kapal Fiber Keterangan :

1. Area Penyimpanan Papan Kayu $(8 \times 2) \mathrm{m}^{2}$

2. Tempat Penyimpanan Peralatan Kayu (1x2) $\mathrm{m}^{2}$

3. Tempat Penyimpanan Peralatan Laminasi $(1 \times 2) \mathrm{m}^{2}$

4. Area Laminasi $(12 \times 21) \mathrm{m}^{2}$

5. Area Fitting $(12 \times 21) \mathrm{m}^{2}$

6. Area Pengecatan dan Pendempulan $(12 \times 21) \mathrm{m}^{2}$

7. Area Peluncuran $(21 \times 6) \mathrm{m}^{2}$

8. Tempat Penyimpanan Permesinan dan Kelistrikan $(3 \times 8) \mathrm{m}^{2}$

9. Tempat Penyimpanan Perlengkapan Outfitting (3x8) $\mathrm{m}^{2}$

10. Area Penyimpanan Material Pengecatan dan Pendempulan $(3 \times 4) m^{2}$

11. Winch $(1 \mathrm{x} 1) \mathrm{m}^{2}$

12. Area Pembangunan Kapal Kayu (21x9) $\mathrm{m}^{2}$

13. Kantor $(6 \times 7) \mathrm{m}^{2}$

14. Mushola (6x5) $\mathrm{m}^{2}$

15. Toilet $(6 \times 6) \mathrm{m}^{2}$

16. Bengkel Las $(3 \times 5) \mathrm{m}^{2}$

17. Area Pelengkungan Papan Kayu (3x6) $\mathrm{m}^{2}$

18. Area Penyimpanan Papan Kayu (3x8) $\mathrm{m}^{2}$

19. Workshop Pengikiran Mata Sawmill $(3 \times 5) \mathrm{m}^{2}$

20. Area Log Kayu $(17 \times 5) m^{2}+(4 \times 35) m^{2}+(5 \times 25) m^{2}$

21. Workshop Penggergajian Kayu (7x30) $\mathrm{m}^{2}$

22. Tempat Penyimpanan Material Laminasi $(3 \times 8) \mathrm{m}^{2}$

Setelah didapatkan kebutuhan tata letak workshop baru galangan, dilakukan analisis biaya pengembangan tata letak workshop galangan UD Duta Merpati. Besaran biaya yang diperlukan meliputi biaya pembongkaran bangunan lama dan biaya pembangunan workshop baru. Kebutuhan biaya pengembangan galangan ini dipaparkan pada Tabel 3 berikut.

Tabel 3. Biaya Pembongkaran Bangunan Lama

\begin{tabular}{cc}
\hline \hline Jenis Biaya & Jumlah Biaya \\
\hline Biaya Pembongkaran Bangunan Lama & 4.590 .000
\end{tabular}


BIaya Pembangunan Bangunan Baru Jumlah

948.600 .000 953.190.000

Dari keseluruhan perhitungan kebutuhan pengembangan galangan, jumlah kebutuhan pengembangan galangan dapat ditampilkan pada Tabel 4 berikut.

Tabel 4. Investasi Kebutuhan Pengembangan Galangan

\begin{tabular}{lc}
\hline \hline \multicolumn{1}{c}{ Jenis Investasi } & Jumlah \\
\hline Pengadaan Pelatihan & 80.000 .000 \\
Pengembangan Peralatan Produksi & 98.023 .000 \\
Pengembangan Workshop & 953.190 .000 \\
\hline \multicolumn{1}{c}{ Total } & $\mathbf{1 . 1 3 1 . 2 1 3 . 0 0 0}$ \\
\hline \hline
\end{tabular}

Perhitungan diatas menunjukkan besar investasi yang diperlukan adalah sebesar Rp.1.131.213.000,-

\section{F. Permasalahan Pengembangan Galangan Kapal Kayu}

Analisis pengembangan galangan kapal kayu sudah dilakukan. Pengembangan ini perlu diadaptasikan dengan kondisi saat ini dimana Kementerian Kelautan dan Perikanan (KKP) tengah mempersiapkan pelelangan pembangunan kapal penangkap ikan. Jika pengembangan ini dilakukan dengan cara konvensional, galangan kapal kayu akan mampu melakukan pembangunan kapal fiber, namun akan melewati masa aktif program pengadaan kapal penangkap ikan oleh KKP tersebut.

Dari analisis yang dilakukan terhadap waktu dan biaya kebutuhan pelatihan terhadap tenaga produksi galangan, didapatkan pembuatan cetakan kapal merupakan masalah terbesar dengan kebutuhan waktu pelatihan selama 50 jam dengan total biaya sebesar 25 juta. Untuk mempersingkat waktu pengembangan galangan kapal kayu, serta untuk mengejar target pembangunan kapal penangkap ikan di tahun 2016, penulis mengusulkan solusi berupa adanya bantuan pemberian cetakan kepada galangan kapal kayu di Jawa Timur.

Bantuan berupa cetakan ini bisa diusulkan kepada Dinas Perindustrian dan Perdagangan Provinsi Jawa Timur. Hal ini dikarenakan Dinas Perindustrian dan Perdagangan Provinsi Jawa Timur menaungi galangan kapal tradisional di Jawa Timur, serta tiap tahun terdapat program pelatihan untuk pengembangan galangan kapal tradisional. Oleh karena itu, dirasa tepat jika program bantuan cetakan yang mampu mempercepat akselerasi kemampuan pengembangan galangan kapal kayu dan membantu program pengadaan kapal oleh Kementerian Kelautan dan Perikanan ini diadakan.

\section{G.Analisis Ekonomis Pengembangan Galangan Kapal Kayu}

Perhitungan analisis ekonomis diperlukan untuk melihat seberapa prospektif galangan kapal kayu jika dilakukan pengembangan. Agar perhitungan bisa dilakukan, harus diketahui pendapatan galangan dan pengeluaran galangan. Setelah kedua hal ini didapatkan, maka perhitungan pun bisa dilakukan dengan melihat berapa besar perbandingan antara investasi yang dilakukan dengan margin keuntungan yang didapatkan.

\section{Pendapatan Galangan}

Pendapatan galangan didapatkan dari keuntungan bersih pembangunan kapal kayu dan pembangunan kapal fiber.

a. Pembangunan Kapal Kayu

Besar biaya produksi kapal kayu didapatkan sebesar : Rp. 1.235.624.250,- Besar keuntungan kapal diasumsikan sebesar $10 \%$ dari biaya produksi, yaitu sebesar Rp.123.562.425,- Dengan target pembangunan kapal sebanyak 1 buah per tahun, maka keuntungan yang bisa didapatkan adalah sejumlah Rp.123.562.425,--

\section{b. Pembangunan Kapal Fiber}

Besar hargakapal fiber dari KKP adalah sebesar Rp. 1.850.000.000. Dengan pengurangan Pajak Pertambahan Nilai (10\%), maka besar harga jual kapal fiber 30 GT adalah Rp. 1.665.000.000,- Dengan besar biaya produksi kapal kayu didapatkan sebesar : Rp. 1.580.239.500,didapatkan harga keuntungan produksi kapal fiber adalah sejumlah Rp. 84.760.500,-

Target pembangunan kapal fiber direncanakan sebanyak 4 buah per tahun, maka potensi keuntungan maksimal yang bisa didapatkan dari pembangunan kapal fiber adalah sejumlah Rp.339.042.000,-

2. Pengeluaran Galangan

Pengeluaran galangan dihitung sebagai nilai investasi yang dikeluarkan saat pengembangan galangan kapal. Jadi, nilai besaran pengeluaran galangan dihitung sebesar Rp 1.131.213.000,-

3. Perhitungan Kelayakan Usaha

Dalam pelaksanaan pengembangan, tidak bisa langsung mencapai titik maksimal produksi dalam tahun awal pelaksanaannya. Oleh karena itu, dilakukan simulasi perolehan pendapatan berdasarkan kemampuan produksi per-tahun dari galangan yang ditampilkan dalam Tabel 5 berikut.

Tabel 5. Perhitungan Keuntungan Galangan Per-Tahun

Berpatokan pada pemasukan galangan tiap tahun yang disampaikan pada Tabel 5, dilakukan perhitungan analisis

\begin{tabular}{cccccc}
\hline \hline Tahun & \multicolumn{2}{c}{$\begin{array}{c}\text { Realisasi } \\
\text { Pembangunan } \\
\text { Kapal }\end{array}$} & \multicolumn{2}{c}{$\begin{array}{c}\text { Besaran Keuntungan } \\
\text { Per-Kapal }\end{array}$} & $\begin{array}{c}\text { Keuntungan } \\
\text { 1 Tahun }\end{array}$ \\
\cline { 2 - 5 } & Fiber & Kayu & Fiber & Kayu & \\
\hline 2016 & 0 & 0 & 0 & 0 & 0 \\
2017 & 1 & 1 & 84.760 .500 & 123.562 .425 & 208.322 .925 \\
2018 & 2 & 1 & 169.521 .000 & 123.562 .425 & 293.083 .425 \\
2019 & 3 & 1 & 254.281 .500 & 123.562 .425 & 377.843 .925 \\
2020 & 4 & 1 & 339.042 .000 & 123.562 .425 & 462.604 .425 \\
2021 & 4 & 1 & 339.042 .000 & 123.562 .425 & 462.604 .425 \\
2022 & 4 & 1 & 339.042 .000 & 123.562 .425 & 462.604 .425 \\
\hline \hline
\end{tabular}

kelayakan usaha berdasarkan metode Net Present Value (NPV) dan Internal Rate of Return (IRR).

Pembiayaan investasi diambilkan dair pinjaman bank. Besaran suku bunga kredit per tahun (i) yang disimulasikan adalah sebesar 13,39\% Per-anum. Maka didapatkan perhitungan NPV yang disajikan dalam Tabel 6 berikut.

Tabel 6. Perhitungan Net Present Value Investasi Galangan

\begin{tabular}{|c|c|c|c|c|c|}
\hline & \multicolumn{2}{|c|}{ Cashflow } & \multirow{2}{*}{$\begin{array}{r}\mathbf{1} /(\mathbf{1}+\mathbf{i})^{\wedge} \mathbf{n} \\
(\mathbf{n}=\text { tahum })\end{array}$} & \multirow{2}{*}{$\begin{array}{l}\text { Net Cash } \\
\text { Inflow }\end{array}$} & \multirow{2}{*}{ NPV } \\
\hline & Out & In & & & \\
\hline 0 & $(1.131 .213,000)$ & & & & $(1.131,213,000)$ \\
\hline 1 & & 208.322 .925 & 0.878 & 183.722 .484 & $(947.490 .516)$ \\
\hline 2 & & 293.083 .425 & 0.771 & 225.914 .346 & $(721.576 .170)$ \\
\hline 3 & & 377.843 .925 & 0.677 & 255.706 .208 & $(465.869 .962)$ \\
\hline 4 & & 462.604 .425 & 0.516 & 238.606 .216 & $(227.055 .088)$ \\
\hline 5 & & 462.604 .425 & 0.437 & 202.208 .658 & $(25.055 .088)$ \\
\hline 6 & & 462.604 .425 & 0.370 & 171.363 .269 & 146.308 .181 \\
\hline 7 & & 462.604 .425 & 0.314 & 145.223.109 & 291.531 .290 \\
\hline
\end{tabular}

Dari perhitungan diatas, didapatkan nilai investasi akan kembali pada tahun ke 6 setelah dilakukan pengembangan. Selanjutnya dihitung kelayakan investasi dengan metode IRR. Perhitungan metode IRR ditujukan untuk melihat berapa besaran bunga bank yang dapat diterima oleh investasi. Pada perhitungan metode NPV, didapatkan investasi kembali pada tahun ke 6. Jadi, tahun ke 6 dijadikan 
patokan sebagai tahun acuan dan besar bunga bank yang berlaku dianggap 13,39\% Per anum

Untuk menghitung IRR, diperlukan discount rate yang menghasilkan NPV negatif dan positif di tahun ke 6 . Dengan acuan :

a. i1 adalah discount rate positif

b. NPV1 adalah Kumulatif NPV i1

c. i2 adalah discount rate negative

d. NPV2 adalah Kumulatif NPV i2

e. Dan NPV adalah besar Investasi

didapatkan masing-masing besaran diatas adalah sebagai berikut ini :
a. $\mathrm{i} 1=18 \%$
b. $\quad \mathrm{NPV}=\mathrm{Rp} \cdot 1 \cdot 413.470 .885,-$
c. i2 $=19 \%$
d. NPV2=Rp.1.375.068.524,-
e. $\quad \mathrm{NPV}=$ Rp. 1.131.213.000,-

Dengan rumus IRR $==\mathrm{i}_{1}+\frac{N P V 1-N P V}{N P V 1-N P V 2}\left(\mathrm{i}_{2}-\mathrm{i}_{1}\right)$, didapatkan besar IRR adalah $=18,03 \%$. Hasil perhitungan IRR $>$ Bunga Bank, sehingga investasi ini disimpulkan layak untuk diterima.

\section{KESIMPULAN DAN SARAN}

Dari hasil penelitian yang dilakukan. dapat diambil kesimpulan sebagaimana berikut :

1. Kondisi eksisting galangan kapal kayu di Jawa Timur rata-rata :

a. Masih melakukan pembangunan kapal secara tradisional, yaitu dengan tanpa adanya desain kapal serta tidak adanya aliran material selama proses pembangunan

b. Lokasi pembangunan kapal menggunakan pesisir pantai atau lahan desa di pinggir pantai

c. Belum memiliki SDM minimal lulusan D3 Teknik Perkapalan sebagai syarat kelayakan galangan mengikuti lelang pembangunan kapal

d. Terdapat galangan yang berpotensial untuk dikembangkan dilihat dari segi fasilitas, luasan workshop, dan legalitas usahanya.

2. Analisis teknis yang dilakukan dalam pengembangan galangan kapal kayu menghasilkan kesimpulan berupa :

a. Peralatan produksi kapal fiber yang digunakan menggunakan peralatan dari metode produksi hand lay-up

b. Pengembangan layout galangan mungkin untuk dikolaborasikan antara produksi kapal kayu dan produksi kapal fiber

c. Besar luasan workshop kapal fiber yang dibutuhkan adalah sebesar $1350 \mathrm{~m}^{2}$ dengan mengurangi area log kayu, menghilangkan area mess karyawan, dan memindahkan bengkel las, gudang papan kayu, serta toilet.

3. Analisa ekonomis yang dilakukan menghasilkan :

a. Pengembangan galangan kapal kayu agar mampu memproduksi kapal fiber dengan metode hand layup membutuhkan investasi sebesar Rp. 1.412.013.000,-

b. Perhitungan kelayakan investasi metode NPV dengan suku bunga 13,39\% menghasilkan pengembalian investasi di tahun ke 6 setelah pengembangan galangan dilakukan.

c. Perhitungan kelayakan investasi metode IRR didapatkan sebesar 18,08\%, lebih besar dari bunga bank yaitu sebesar 13,39\%. Sehingga disimpulkan IRR > MARR, dan investasi layak untuk dilakukan.

4. Kebutuhan pengembangan SDM galangan kapal kayu diantaranya membutukan :

a. Komposisi manajemen galangan berupa direktur utama (owner), kepala produksi (minimal D3 Teknik Perkapalan), tenaga produksi, tenaga kelistrikan (minmal SMK Listrik), administrasi dan keuangan, serta bagian pemasaran.

b. Pengembangan kompetensi tenaga produksi kapal fiber membutuhkan 35 materi pelatihan selama 160 jam yang terdiri dari teori dan praktek.

5. Permasalahan dan solusi pengembangan galangan kapal kayu diantaranya adalah :

a. Waktu pengembangan galangan kapal kayu yang terbatas, disebabkan pelaksanaan program pengadaan kapal penangkap ikan oleh Kementerian Kelautan dan Perikanan tengah berjalan

b. Kompetensi sumberdaya manusia galangan kapal kayu saat ini belum mampu untuk membuat bagian cetakan kapal fiber.

c. Solusi yang diusulkan adalah pemberian bantuan berupa cetakan kapal fiber kepada galangan kapal kayu di Jawa Timur, oleh Dinas Perindustrian dan Perdagangan Provinsi Jawa Timur yang menanungi pelatihan dan pembinaan galangan kapal tradisonal Jawa Timur. Hal ini perlu dilakukan agar galangan kapal tradisional Jawa Timur mampu ambil bagian dalam pembangunan kapal penangkap ikan oleh Kementerian Kelautan dan Perikanan.

Saran yang bisa disampaikan untuk peningkatan kemampuan galangan kapal kayu di Jawa Timur adalah :

1. Menyikapi permasalahan waktu pengembangan galangan kapal kayu di Jawa Timur yang terbatas, serta mengejar kebutuhan pembangunan kapal penangkap ikan yang tengah berjalan, Dinas Perindustrian dan Perdagangan Provinsi Jawa Timur bisa bekerjasama dengan salah satu instansi di Jawa Timur untuk melakukan pembuatan cetakan kapal fiber secara massal agar dapat diperbantukan kepada galangan kapal kayu di Jawa Timur.

2. Kapal fiber memiliki kelemahan berupa berat kapal yang ringan, yang menyebabkan kapal tidak stabil pada saat berlayar dengan muatan kosong. Dengan jumlah galangan kapal kayu yang lebih dominan dibandingkan jumlah galangan kapal fiber, serta untuk mengurangi resistansi masyarakat terhadap penggunaan kapal fiber, bisa dilakukan studi pembangunan kapal fiber menggunakan konstruksi sandwich dengan core material berupa kayu. Hal ini mampu mengurangi kelemahan kapal fiber yang terlalu ringan, mengurangi resistansi nelayan, serta mampu memaksimalkan sumberdaya kayu yang dimiliki oleh galangan.

\section{DAFTAR PUSTAKA}

[1] Direktorat Jenderal Perikanan Tangkap. (2015). Kebijakan Pengembangan dan Pembinaan Kapal Perikanan dan Alat Penangkap Ikan. Pekanbaru : Kementerian Kelautan dan Perikanan

[2] Direktorat Jenderal Perikanan Tangkap. (2015). Rencana Pengembangan Armada Perikanan Nasional. Jakarta : Kementerian Kelautan dan Perikanan

[3] Hutapea, Tamba. (2015). BKPM Petakan 12 Wilayah Industri Galangan Kapal.Dipetik September 10,2015 dari Antaranews.com : http://www.antaranews.com/berita/505570/bkpm-petakan-12wilayah-industri-galangan-kapal 
[4] Dinas Perindustrian dan Perdagangan Provinsi Jawa Timur. (2013). Data IKM Kapal Rakyat Provinsi Jawa Timur. Surabaya

[5] Undang-undang Republik Indonesia. (2004). Undang-Undang Tentang Perikanan. Jakarta

[6] Coackley, Ned. (1991). Fishing Boat Construction : 2. Building a Fibreglass Fishing Boat. Roma : FAO Fisheries Technical Paper

[7] Soejitno. (1996). Galangan Kapal. Surabaya : Institut Teknologi Sepuluh Nopember

[8] Widjaja, Sjarief. (1996). Manajemen Produksi untuk Industri Perkapalan. Surabaya : Institut Teknologi Sepuluh Nopember

[9] Anityasari, Maria dan Wessiani, Naning Aranti. 2011. Analisis Kelayakan Usaha dilengkapi Kajian Manajemen Resiko. Surabaya : Guna Widya 